\title{
INVESTIGATING THE COST OF MODERN CONSTRUCTION IN YEMEN
}

\author{
Basel Sultan \\ Engineering Management Department, College of Engineering, \\ Prince Sultan University, P O Box 66388, Riyadh 11586, Saudi Arabia \\ Wael Alaghbari \\ Architecture Department, Faculty of Engineering, University of Sana'a, \\ P. O. Box: 16363, Sana'a, Yemen
}

\begin{abstract}
The recent changes in the construction industry (CI) of Yemen have generated a transition from traditional to modern construction. Modern construction depends principally on imported building materials, which are very expensive. In most cases, a cost reduction is attained, by lowering the construction quality, as a result leading to non-attractive and less durable and more costly buildings. A survey was conducted locally in this paper, to investigate the construction costs of structural and finishing elements; the outcome showed that the cost of structural elements is the major contributor to high construction costs. Based on this outcome, a Delphi method is performed, to list experts' most crucial recommendations that are needed to enhance the situation in Yemen.
\end{abstract}

Keywords: Cost, Structural Element, Construction Materials, Finishing Element, Yemen, Developing Countries.

Cite this Article: Basel Sultan and Wael Alaghbari, Investigating the Cost of Modern Construction in Yemen. International Journal of Civil Engineering and Technology, 11(3), 2020, pp. 97-104.

https://iaeme.com/Home/issue/IJCIET?Volume=11\&Issue=3

\section{INTRODUCTION}

The increasing demand in construction infrastructure projects and the low production of local construction materials has made the construction and material industries in Yemen unable to meet current demand to an increasing reliance on imports. The (CI) in developing countries depend significantly on imported materials that comprise up to 50-60\% of the total construction cost [1]. Miles [2] has highlighted the problem of this severe reliance on imports in the (CI) in Yemen; where imported materials comprise $60-70 \%$ of the overall cost.

Although, the developing countries, have recognised that there is little motivation for a shift to sustainability if it is costly and not within the local and traditional capabilities. 
Traditionally, Yemen has created a distinctive building tradition, and consistent architectural style, this building tradition had to be well sustained. However, the urgent need for housing and infrastructure construction projects, with the growing drift towards modernisation in Yemen has initiated a transformation from traditional to modern building construction. These modern buildings depend mainly on imported technologies and materials, which are generally costly. Current reports have shown that the local construction industry is not able to adjust and develop competent managerial and technical expertise and ability to deal with and manage the fast growth and the high demand for these modern construction systems [4].

A previous survey by Sultan [5] showed that the main cause of high construction costs is imported construction materials and the excessive waste in the new construction practices. Ironically, the stakeholders believe that the problems in local materials and construction practices had an unimportant effect on construction cost and waste.

Sultan and Kajewski [4] indicated that some of the particular problems connected with the (CI) in Yemen linked directly to the inexplicit and unclear construction practices and technologies, in addition to, the inclination of the stakeholders and owners to reduce the construction costs by minimizing or eliminating engineering and technical services. This intention to decrease the construction cost has only led to overdesigns, excessive and unnecessary utilization of construction materials, excessive waste, moreover, lower quality finishing in most new construction projects. Furthermore, there is a tendency to use unnecessary structural elements (Figure 1). Moreover, the absence of any national codes, standards, which has only lead to designs that are not in consistency with local requirements and priorities.
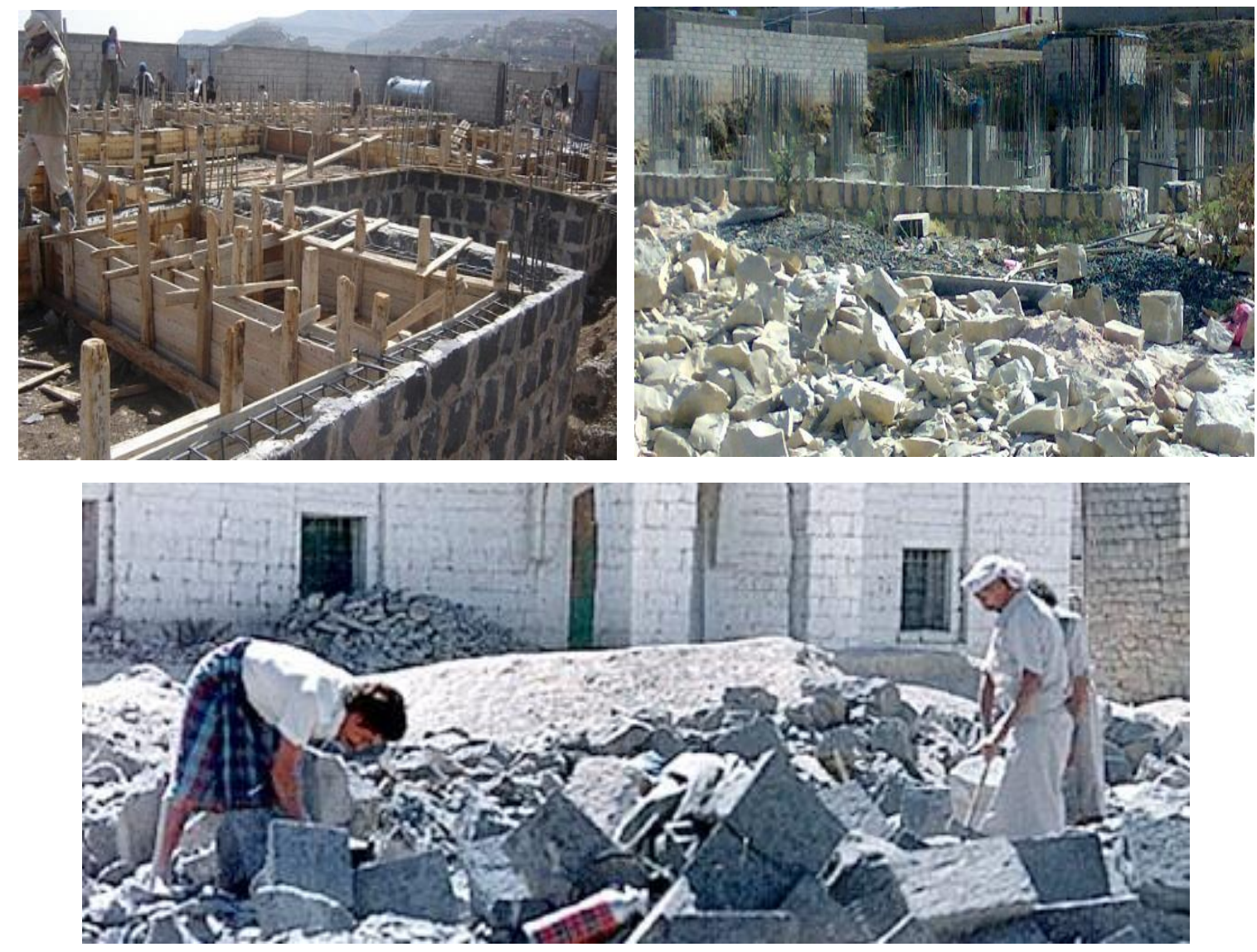

Figure 1 Modern-Traditional Buildings with Unnecessary Structural Elements and Excessive Waste 
Tassios [6] stated that the ratio ( 1 ) of the cost of structural elements to the cost of the finishing elements, reflects the state of the construction development. Generally, in the developed countries the ratio $(\lambda)$ is $1: 4$, and in rapidly developing countries, such as Brazil, the ratio $(\lambda)$ is $1: 2$, and developing countries, the ratio $(\lambda)$ is $1: 1$.

Table 1 Percentages of Cost by Elements in Modern Construction

\begin{tabular}{|lccc|}
\hline & $\begin{array}{c}\text { Structural } \\
\mathbf{\%}\end{array}$ & $\begin{array}{c}\text { Finishing } \\
\text { \% }\end{array}$ & $(\boldsymbol{\lambda})$ \\
\hline Kenya & 63.2 & 36.8 & $1: 0.6$ \\
Ghana & 53.5 & 46.5 & $1: 0.8$ \\
Senegal & 49 & 51 & $1: 1.1$ \\
Developed countries & 20 & 80 & $1: 4.0$ \\
\hline
\end{tabular}

Source: Tassios [6]

This paper looks at the background of the local (CI) in Yemen and then uses a survey to verify that structural elements cost in a modern building is the major contributor to overall construction cost. Based on this, this paper uses a Delphi method to seek experts' opinions and recommendations required to improve the situation.

\section{TRADITIONAL AND MODERN CONSTRUCTION IN YEMEN}

Yemen has a distinctive inheritance of traditional buildings and construction [8] \& [7]. Traditional structure in Yemen uses local construction materials and the employment of local construction techniques and methods (Figure 2). The structure could have load-bearing walls built from earth blocks, or stone, this depends on the locally available materials in the region. The advantages of this traditional construction type were mainly that the designs met the needs of the environment [9].

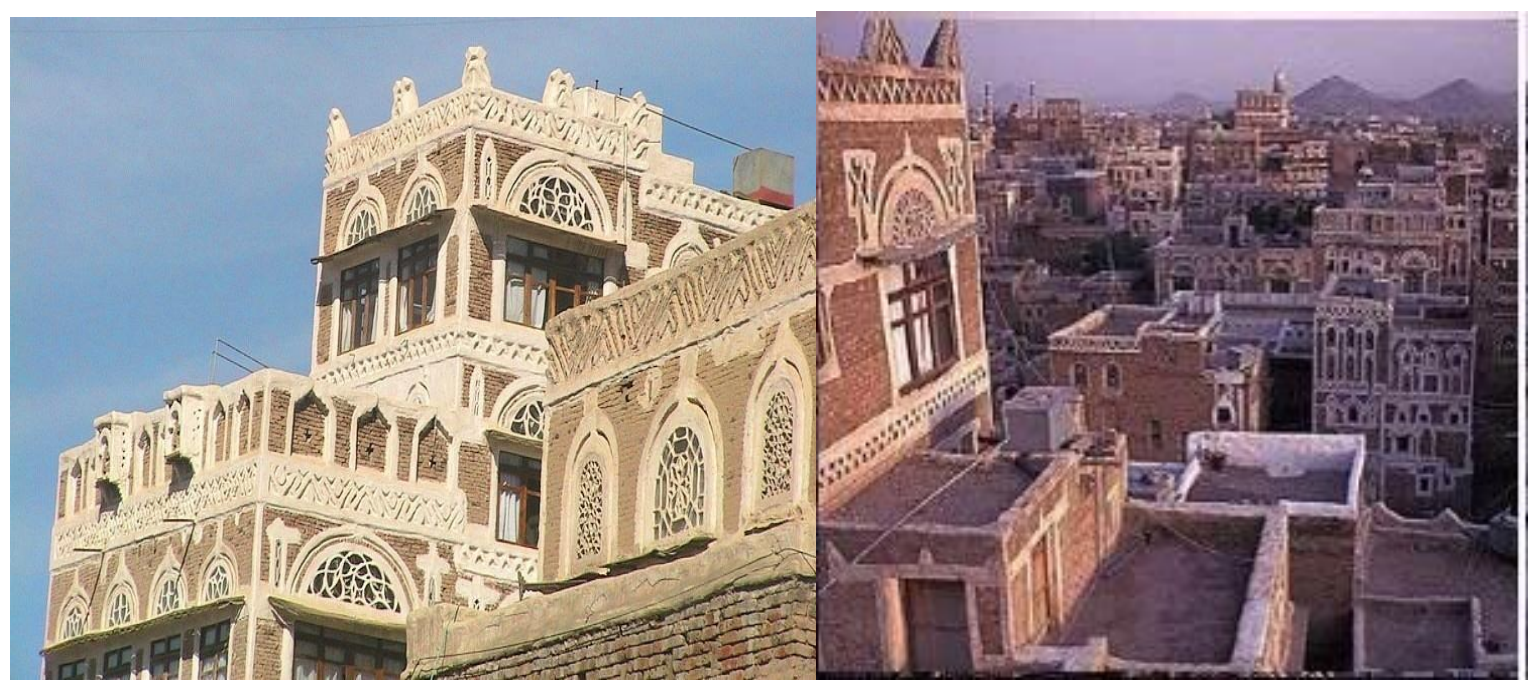

Figure 2 Traditional Construction in Sana'a

The buildings built using traditional construction materials and methods served well. Natural stone has been the traditional material for mountain areas (Figure 3); different types of natural stones for external walls and footings, also mud bricks used for external walls. The traditional materials in warm and humid coastal regions are mud bricks, while the natural stone is uncommon. However, the extensive usage of local construction materials is restrained by their insufficient quantity, high cost and poor quality [8]. Moreover, stone trimmed manually by hand is the conventional material in the highlands. Yet, because of low 
productivity of construction labour [10] and the high cost, new mechanical methods stone cutting and quarrying have been introduced.

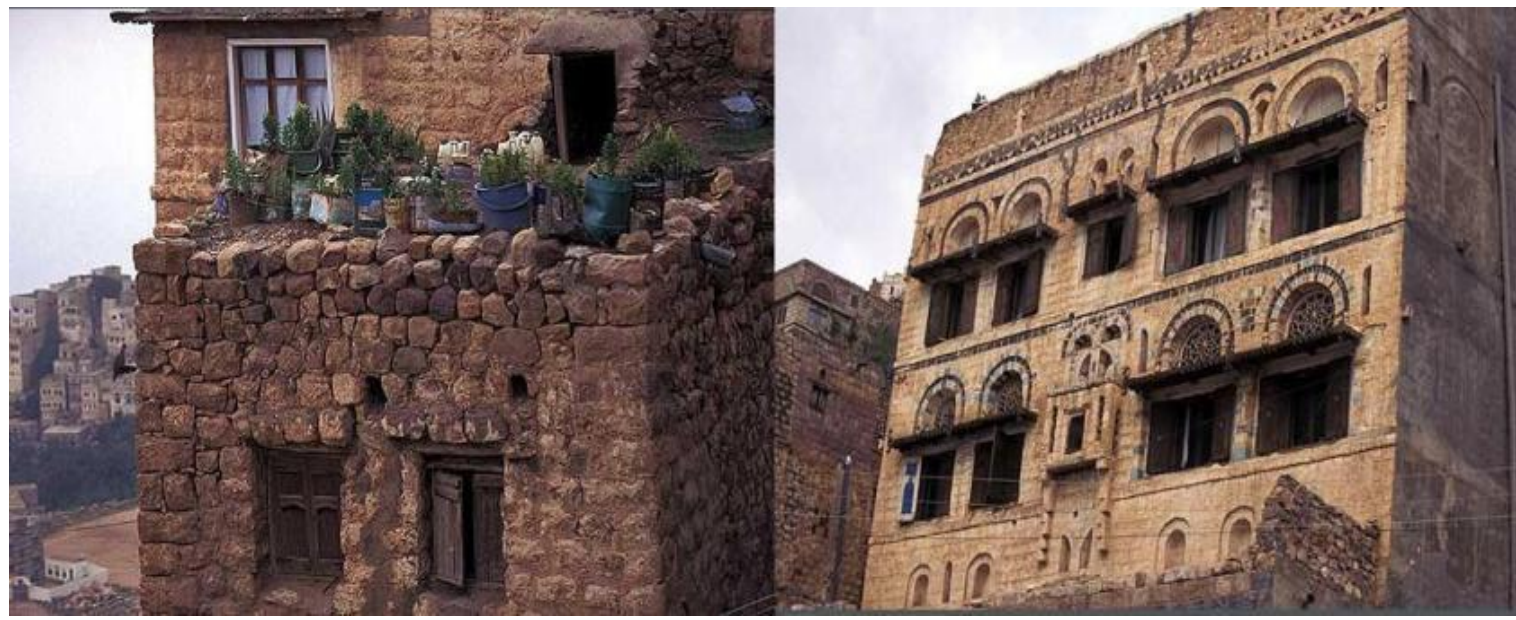

Figure 3 Traditional Stone Buildings in Mountain Areas

The Ministry of Public Works (MOPW) in the past invited international organisations to assist in its socioeconomic development [3]. However, with practically no managerial and technical workforces, it was difficult for the Ministry to regulate and control the urgent infrastructure supplies, which has generated a state of 'free for all'. Moreover, the construction materials manufactured by the private sector were insufficient to meet the construction projects demand. The demand for new materials increased, all that had increased prices and the low quality of the construction materials [9]. The required import policies for the $(\mathrm{CI})$ were absent. After the import of modern construction materials introduced new construction methods, while local traditions pushed backwards. The local Yemeni traditional experience and knowledge concerning the local materials rapidly disappeared .
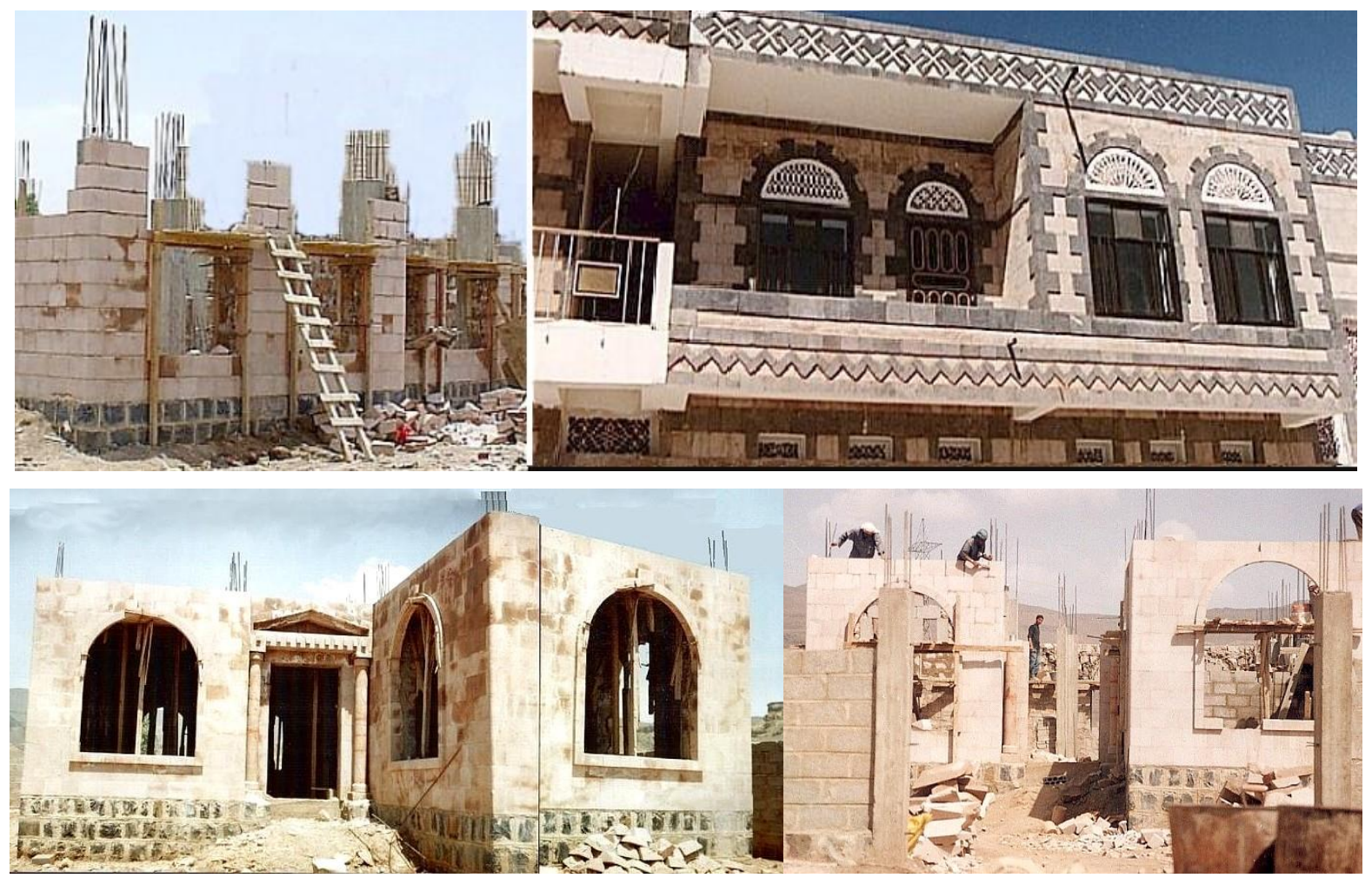

Figure 4 Modern-Traditional Buildings 
Modern buildings in Yemen defined as buildings constructed, generally in the cities. In those urban areas, construction frequently carried out using advanced techniques, typically reinforced-concrete structural skeleton. The exterior walls of structurally reinforced-concrete building units are built of cement blocks or indigenous stones to replicate the traditional style (Figure 4), which is a mix of modern and traditional construction that is expensive.

However, in dry mountain environments, reinforced-concrete structural frame building repeatedly disregards the regional environmental conditions, where concrete walls do not have adequate thermal insulation. Furthermore, the expansion stresses created by the changes in the temperatures, quickly deteriorate the structure. In the hot weather in coastal areas, modern buildings where walls made of cement blocks, always provide minimum thermal comfort, and the concrete and plaster deteriorate quickly from the salinity and humidity of the air (Figure 5).

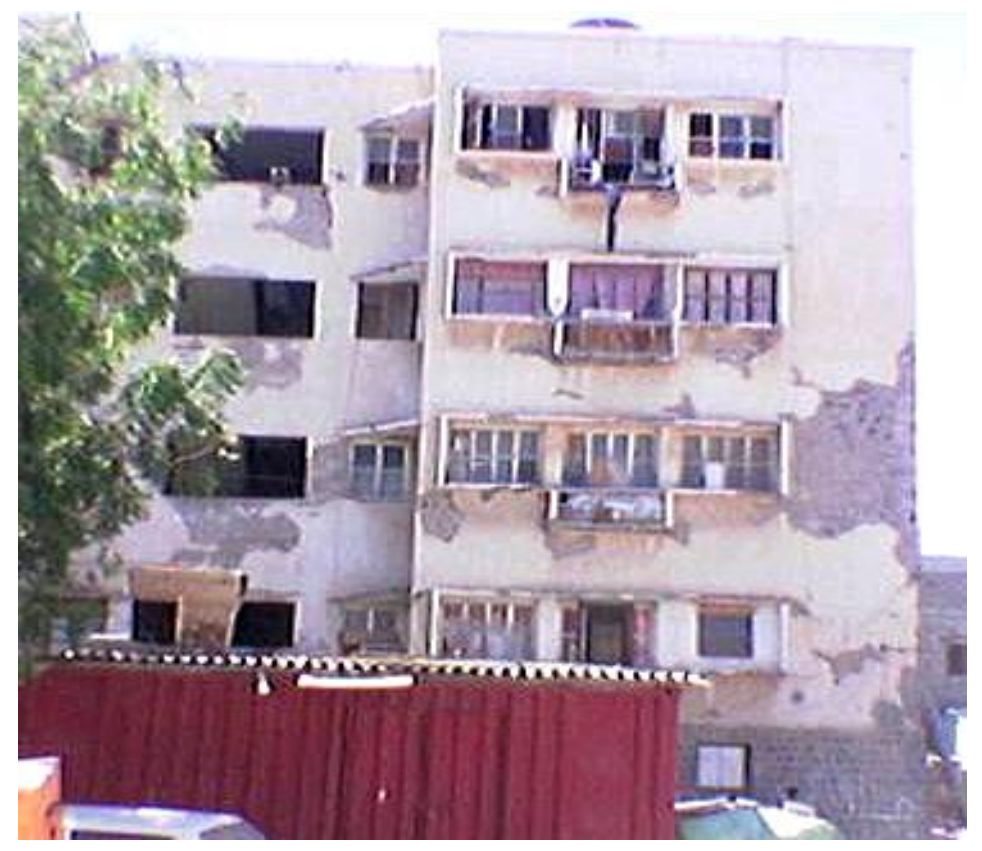

Figure 5 Low-Quality Finishing in Modern Buildings

At present Ordinary Portland Cement (OPC) is the essential material in Yemen. Ordinary Portland cement becomes the most fundamental construction material in which the government is involved in. Nonetheless, the excessive usage and dependence on Ordinary Portland Cement (OPC) with the shortage in production, together with high market demand have constrained the output of the (CI) in Yemen and led to constant increases in the price of Ordinary Portland Cement (OPC). The rapid and chaotic switch to modern technology due to the crucial and pressing needs for housing and infrastructure projects has led to control and regulatory problems. The lack of research has made it difficult to recognize, monitor and control the defects in the construction sector.

\section{METHODOLOGY}

Initially, this paper briefly highlights the construction industry historical background in Yemen, and then conducted a local survey to examine the ratio $(\lambda)$, then verify if the structural elements are the primary cause to high construction costs in Yemen. In light of the outcome, the research conducts a Delphi method on a selected group of construction experts' to identify and confirm essential recommendations needed to enhance this situation in the modern types of construction projects in Yemen. 


\subsection{Local Survey}

A local survey methodology considered here as the most appropriate method to address the research's objectives. A total of 49 local stakeholders requested to state their expected percentage of cost distribution in the structural and finishing elements in the new modern types of building structures, as encountered in Yemen construction sector.

Typically, the outcome indicated that the structural elements are responsible for about $53.1 \%$ of the total construction cost. In contrast, the finishing elements composed $46.9 \%$ of the total cost. Therefore, the ratio $(\lambda)$ in Yemen, was estimated to be 1:0.88, which is high in comparison with the 1:4 found in developed countries as shown in Table 1, this outcome verifies that the cost of structural elements in the modern types buildings is the major contributor to the construction cost in Yemen.

Table 2 Percentages of Construction Elements Cost

\begin{tabular}{|cccc|}
\hline & $\begin{array}{c}\text { Structural } \\
\boldsymbol{\%}\end{array}$ & $\begin{array}{c}\text { Finishing } \\
\text { \% }\end{array}$ & $\boldsymbol{\lambda}$ \\
\hline Yemen & 53.1 & 46.9 & $1: 0.88$ \\
\hline
\end{tabular}

Source: Local survey

As debated by the survey's participants, the main causes of the magnified use of structural elements are:

- Obscure construction practices;

- Lack of information on material specifications;

- Wasteful use of stone in external stone walls;

- Incompetent production and delivery of local materials; and

- Overdesigned construction practices.

Based on this outcome, a Delphi method performed, to obtain experts' census to the most crucial recommendations that are needed to enhance the situation in Yemen.

\subsection{Delphi Questionnaire}

Table 2 Delphi Final Round

\begin{tabular}{|c|c|c|c|c|c|c|c|c|c|c|c|c|c|c|}
\hline \multirow{3}{*}{$\begin{array}{l}\text { Recommended } \\
\text { Construction Practices }\end{array}$} & \multicolumn{11}{|c|}{ Ranking } & \multirow{3}{*}{ 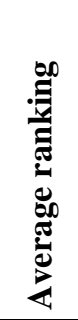 } & \multirow{3}{*}{ 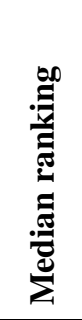 } & \multirow{3}{*}{ 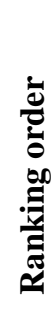 } \\
\hline & \multicolumn{3}{|c|}{ 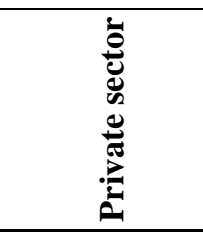 } & \multicolumn{4}{|c|}{ 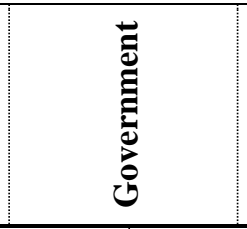 } & \multicolumn{4}{|c|}{ 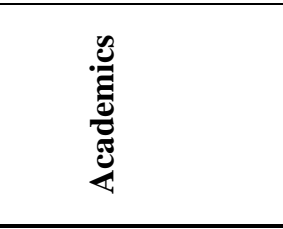 } & & & \\
\hline & $\mathbf{A}$ & $\mathbf{B}$ & $\mathbf{C}$ & D & $\mathbf{E}$ & $\mathbf{F}$ & $\mathbf{G}$ & $\mathbf{H}$ & $\mathbf{I}$ & $\mathbf{J}$ & $\mathbf{K}$ & & & \\
\hline Improve site supervision maximize productivity & 5 & 3 & 2 & 3 & 4 & 2 & 6 & 3 & 3 & 3 & 2 & 3.3 & 3.0 & 3 \\
\hline Minimise the use of imported materials & 4 & 1 & 8 & 4 & 7 & 1 & 9 & 6 & 9 & 7 & 5 & 5.5 & 6.0 & 5 \\
\hline $\begin{array}{l}\text { Efficient production and utilisation of local } \\
\text { materials }\end{array}$ & 7 & 5 & 3 & 6 & 5 & 8 & 8 & 4 & 6 & 4 & 3 & 5.4 & 5.0 & 4 \\
\hline $\begin{array}{l}\text { Efficient use of designs and construction practices } \\
\text { in structural elements }\end{array}$ & 1 & 4 & 6 & 2 & 1 & 3 & 2 & 2 & 1 & 2 & 1 & 2.3 & 2.0 & 1 \\
\hline Minimise site waste by using skilled labour & 6 & 6 & 7 & 5 & 2 & 7 & 3 & 9 & 8 & 5 & 6 & 5.8 & 6.0 & 6 \\
\hline $\begin{array}{l}\text { Provide clear construction code of practices and } \\
\text { standards }\end{array}$ & 3 & 7 & 1 & 1 & 3 & 4 & 1 & 1 & 2 & 1 & 4 & 2.5 & 2.0 & 2 \\
\hline
\end{tabular}

Ranking: 1-2 important, 3-4 less important and 5-6 is not important 
A Delphi questionnaire carried on eleven experts that they were asked to give their opinions on the most urgent practices that are needed to improve local construction practices. The experts were asked to rank the most required Construction Practices. Two Delphi rounds were applied, and the final ranking of these practices in terms of importance is summarized in Table 2.

\section{DISCUSSION}

Considering the local situation in the material and construction industries in Yemen, these are subsequent recommendations are suggested in acceptable order; as a result, of the local experts' census:

- It is essential to use effective \& well-defined structural design and construction practices. These construction practices should efficiently use more locally available materials.

- It is necessary to develop well-defined construction standards and construction regulations.

- Improve site supervision and maximize productivity.

- Improve national efficiency in producing and utilising local materials. Specifically, promote effective production and distribution of local materials according to its environmental suitability and the local requirements.

Minimizing the use of imported materials for improving the situation is not considered urgent by the experts. However, should reduce site waste by using skilled labour, and improve supervision activities and training. Moreover, it is suggested by experts the need to generate suitable traditional construction models, which recognizes and sustain the local cultural heritage and resources.

\section{CONCLUSION}

The pressing demand for housing and infrastructure projects in Yemen has caused a rapid shift to modern construction designs and practices; these modern structures are overdesigned, costly and have poor finishing quality.

This paper assessed the construction in Yemen by investigating cost percentages of structural and finishing costs to total construction costs. The cost of structural elements found to be relatively higher than usual; this is due to many reasons, mainly due to overdesign and excessive waste practices. To adjust the situation, experts recommended that the construction industry should initially resolve the problems associated with the design and construction of the structural elements, furthermore, develop appropriate local construction practices and standards that are efficient and that recognize and sustain local priorities, resources and environment.

\section{DECLARATION OF CONFLICT OF INTERESTS}

The author has declared no conflict of interests.

\section{REFERENCES}

[1] Edmonds G. A. 'The construction industry in developing countries', International Labour Review, Vol. 118, No. (3), pp 355-369, 1979.

[2] Miles D. 'Yemen Arab Republic: the construction industry. Development and Urban Metamorphosis', The Aga Khan Award for Architecture, Vol. 2:, 1984. 
[3] H. Sameh, A. El Zafrany and D. N. Attiya, Analysis of Thermal Comfort Enhancement Using Vernacular Architecture in Siwa Oasis, Egypt, Journal of Engineering and Applied Science, Vol. 66, No. 6, Dec. 2019, Pp. 679-701, Faculty Of Engineering, Cairo University.

[4] Sultan, B. and Kajewski, S., 'The Yemen Construction Industry: Readying the Industry for the Successful Implementation of Sustainability', in: Proceeding of the International Conference on Smart and Sustainable Built Environment (SASBE2003) Brisbane, Australia, November $19^{\text {th }}-21^{\text {st }}, 2003$.

[5] Basel Sultan (2013), Impediments to the Construction Industry Development Of Yemen, Journal of Science and Technology, Vol 18, No. 2, 2013.

[6] Tassios S. 'Structure \& Function of the Construction Industry with Emphasis on Developing Countries'. Paper no. ID/WG.528/1 prepared for the meeting of UNIDO and UNCHS (Habitat), First Consultation on the Construction industry, Tunis, Tunisia. 1993.

[7] United Nations Industrial Development Organization (UNIDO) and World Bank Cooperative Programme, 'Yemen Arab Republic: The Construction Industry', Vienna, Report no. 17, 1981.

[8] Kulkarni B. V., 'A Construction Industry in Transition. Development and Urban Metamorphosis'; Vol. 1: Yemen at the Cross-Roads. Evin, Ahmet (ed). Singapore: Concept Media, The Aga Khan Award for Architecture. 1983.

[9] Wael Alaghbari, Abubaker A. Al-Sakkaf, and Basel Sultan, Factors Affecting Construction Labour Productivity in Yemen, International Journal of Construction Management, VOL. 19, NO. 1, 79-91, 2019.

[10] Basel Sultan, Wa'el Alaghbari, Priorities for Sustainable Construction Industry Development in Yemen, International Journal of Applied Engineering Research, Vol. 12, No. 6, pp. 886-893, 2017. 